\title{
Skin Manifestations in COVID-19: Prevalence and Relationship with Disease Severity
}

\author{
Priscila Giavedoni ${ }^{1,+}$, Sebastián Podlipnik ${ }^{1,+}{ }^{+}$, Juan M. Pericàs ${ }^{2}$, Irene Fuertes de Vega ${ }^{1}$ (i), \\ Adriana García-Herrera ${ }^{3}{ }^{(0)}$, Llúcia Alós ${ }^{3}{ }^{\circledR}$, Cristina Carrera ${ }^{1}$ () , Cristina Andreu-Febrer ${ }^{1}$, \\ Judit Sanz-Beltran ${ }^{1} \mathbb{D}$, Constanza Riquelme-Mc Loughlin ${ }^{1}{ }^{\circledR}$, Josep Riera-Monroig ${ }^{1}{ }^{\circledR}$, \\ Andrea Combalia ${ }^{1}$, Xavier Bosch-Amate ${ }^{1}$ D , Daniel Morgado-Carrasco ${ }^{1}$, Ramon Pigem ${ }^{1}$, \\ Agustí Toll-Abelló ${ }^{1}$, Ignasi Martí-Martí ${ }^{1}$, Daniel Rizo-Potau ${ }^{1}$, Laura Serra-García ${ }^{1}$, \\ Francesc Alamon-Reig ${ }^{1}{ }^{(\mathbb{D}}$, Pilar Iranzo ${ }^{1}$, Alex Almuedo-Riera ${ }^{4}\left(\mathbb{D}\right.$, Jose Muñoz ${ }^{4}$, Susana Puig ${ }^{1,5}$ \\ and José M. Mascaró Jr. ${ }^{1, *}$ \\ 1 Dermatology Department, Hospital Clinic of Barcelona, University of Barcelona, Barcelona 08036, Spain; \\ pgiavedo@clinic.cat (P.G.); podlipnik@clinic.cat (S.P.); ifuertes@clinic.cat (I.F.d.V.); ccarrera@clinic.cat (C.C.); \\ cristina.af20@gmail.com (C.A.-F.); juditsanzb@gmail.com (J.S.-B.); MCRIQUELME@clinic.cat (C.R.-M.L.); \\ jrieramonroig@gmail.com (J.R.-M.); andreacombalia@gmail.com (A.C.); \\ xavi_bosch92@hotmail.com (X.B.-A.); morgadodaniel8@gmail.com (D.M.-C.); \\ ramon.pigem@gmail.com (R.P.); atoll@clinic.cat (A.T.-A.); ignasi.marti.marti@gmail.com (I.M.-M.); \\ danielrizopotau@msn.com (D.R.-P.); lserra94@gmail.com (L.S.-G.); francescalamonreig@gmail.com (F.A.-R.); \\ piranzo@clinic.cat (P.I.) \\ 2 Infectious Diseases Department, Hospital Clinic of Barcelona, University of Barcelona, \\ Barcelona 08036, Spain; pericasjm@gmail.com \\ 3 Pathology Department, Hospital Clinic of Barcelona, University of Barcelona, Barcelona 08036, Spain; \\ apgarcia@clinic.cat (A.G.-H.); lalos@clinic.cat (L.A.) \\ 4 International Health Department ISGlobal, Hospital Clinic, University of Barcelona; Barcelona 08036, Spain; \\ aalmuedo@gmail.com (A.A.-R.); JMUNOZG@clinic.cat (J.M.) \\ 5 CIBER de Enfermedades Raras, Instituto de Salud Carlos III, Barcelona 08036, Spain; spuig@clinic.cat \\ * Correspondence: jmmascaro_galy@ub.edu; Tel.: +34-93-2275586; Fax: +34-93-4514438/5424 \\ + These authors contributed equally to this work.
}

Received: 27 August 2020; Accepted: 9 October 2020; Published: 12 October 2020

\begin{abstract}
Background: Data on the clinical patterns and histopathology of SARS-CoV-2 related skin lesions, as well as on their relationship with the severity of COVID-19 are limited. Methods and Materials: Retrospective analysis of a prospectively collected cohort of patients with SARS-CoV-2 infection in a teaching hospital in Barcelona, Spain, from 1 April to 1 May 2020. Clinical, microbiological and therapeutic characteristics, clinicopathological patterns of skin lesions, and direct immunofluorescence and immunohistochemical findings in skin biopsies were analyzed. Results: Fifty-eight out of the 2761 patients (2.1\%) either consulting to the emergency room or admitted to the hospital for COVID-19 suspicion during the study period presented COVID-19 related skin lesions. Cutaneous lesions could be categorized into six patterns represented by the acronym "GROUCH": Generalized maculo-papular (20.7\%), Grover's disease and other papulo-vesicular eruptions (13.8\%), livedo Reticularis (6.9\%), Other eruptions (22.4\%), Urticarial (6.9\%), and CHilblain-like (29.3\%). Skin biopsies were performed in $72.4 \%$, including direct immunofluorescence in $71.4 \%$ and immunohistochemistry in $28.6 \%$. Patients with chilblain-like lesions exhibited a characteristic histology and were significantly younger and presented lower rates of systemic symptoms, radiological lung infiltrates and analytical abnormalities, and hospital and ICU admission compared to the rest of patients. Conclusion: Cutaneous lesions in patients with COVID-19 appear to be relatively rare and varied. Patients with chilblain-like lesions have a characteristic clinicopathological pattern and a less severe presentation of COVID-19.
\end{abstract}


Keywords: COVID-19; skin lesions; chilblain; histopathology; coronavirus; pandemic

\section{Introduction}

Coronavirus disease 2019 (COVID-19), caused by severe acute respiratory syndrome coronavirus 2 (SARS-CoV-2), has rapidly spread to acquire pandemic proportions since the first outbreak was declared in Wuhan, the capital of Hubei Province, China, in December 2019 [1].

Although the most common manifestations of COVID-19 are fever and respiratory symptoms such as cough and shortness of breath, other manifestations are also relevant, and subacute manifestations such as organizing pneumonia and decreased pulmonary function, or drug interactions and side effects are increasingly gaining attention as the knowledge on COVID-19 pathophysiology and natural history accumulates [2-9].

Recently, skin lesions have been described as potential manifestations of COVID-19. The skin changes reported to date include erythematous rash, urticaria, livedo reticularis, vesicular lesions, and chilblain-like lesions [10-15]. However, there are insufficient data on the prevalence and histopathology of skin lesions associated with COVID-19, as well as the associated clinical, analytical, and radiological findings.

This study was aimed to characterize the prevalence, clinical features, and histopathology findings of COVID-19-associated skin manifestations and their relationship with other COVID-19 clinical-epidemiological features.

\section{Methods}

\subsection{Design}

Single-center prospective cohort study carried out from 1 April to 1 May 2020. This study was performed following the STROBE guidelines [16].

\subsection{Setting}

Hospital Clínic de Barcelona is an 800-bed tertiary university hospital providing care to 600,000 people in the metropolitan area of Barcelona, Spain.

\subsection{Patients}

Consecutive patients with diagnosis of COVID-19 presenting new-onset of skin lesions. All consultations to the Dermatology Department originated from the Emergency Department, hospital wards, or intensive care units. The performance of skin biopsies was assessed in all patients and performed reaching a consensual agreement between the patient and the treating physician. Histologic studies requested included hematoxylin and eosin (HE) stain, direct immunofluorescence (DIF), and immunohistochemistry (IHC). DIF was performed on cryostat sections using FITC-conjugated antibodies to IgG, IgM, IgA, C3 and fibrinogen. In addition, we tested complement C9 expression by immunohistochemistry on paraffin sections of formalin-fixed tissue. Assays for detection of SARS-CoV-2 in skin samples were not done.

Real-time polymerase chain reaction (rt-PCR) from nasopharyngeal swabs was carried out amplifying the betacoronavirus $E$ gene and the specific SARS-CoV-2 RdRp gene (Roche ${ }^{\circledR}$; sensitivity $90 \%$ and specificity $100 \%$ ). A serology kit was set up in our immunology laboratory for the detection of IgA, IgM or IgG SARS-CoV-2-specific antibodies (sensitivity $97 \%$ for IgA and IgG, 75\% for IgM, and specificity of $100 \%$ for IgG and IgM and $98 \%$ for IgA). Diagnosis of COVID-19 included confirmed cases with positive microbiological tests and highly suspected cases, which were managed according to our institutional protocols as being infected (isolation measures \pm antiviral therapies) based on highly suggestive epidemiological, clinical, radiological, and analytical features. See in Supplementary Material. 


\subsection{Ethics}

The Hospital Clínic Ethical Board approved this study (HCB/2020/0581) and waived the requirement for informed consent due to the ongoing situation of infectious disease emergency.

\subsection{Statistical Analysis}

A descriptive analysis of the characteristics of patients presenting skin lesions associated with COVID-19 was carried out, as well as a univariate analysis of selected categories comparing patients with chilblain-like lesions and patients with other type of lesions. Categorical variables were summarized as percentages and compared through the Pearson Chi-square test or Fisher exact test when appropriate. Continuous variables were summarized as median and interquartile ranges (IQR) and compared using ANOVA test or $T$ test. $p$ values $<0.05$ were considered statistically significant. Computing environment R (v 4.0.0, Foundation for Statistical Computing, Vienna, Austria) was used.

\section{Results}

During the study period, a total of 2761 patients either consulted to the Emergency Department (593) or were admitted to the hospital (2168) with a COVID-19 suspicion (Figure 1). In the same period, the Dermatology Department received 110 consultations, of which 70 had initial suspicion of COVID-19 related skin lesions. The final sample size consisted of 58 patients $(2.1 \%$ of overall patients and $52.7 \%$ of dermatologic consultations) with diagnosis of COVID-19.

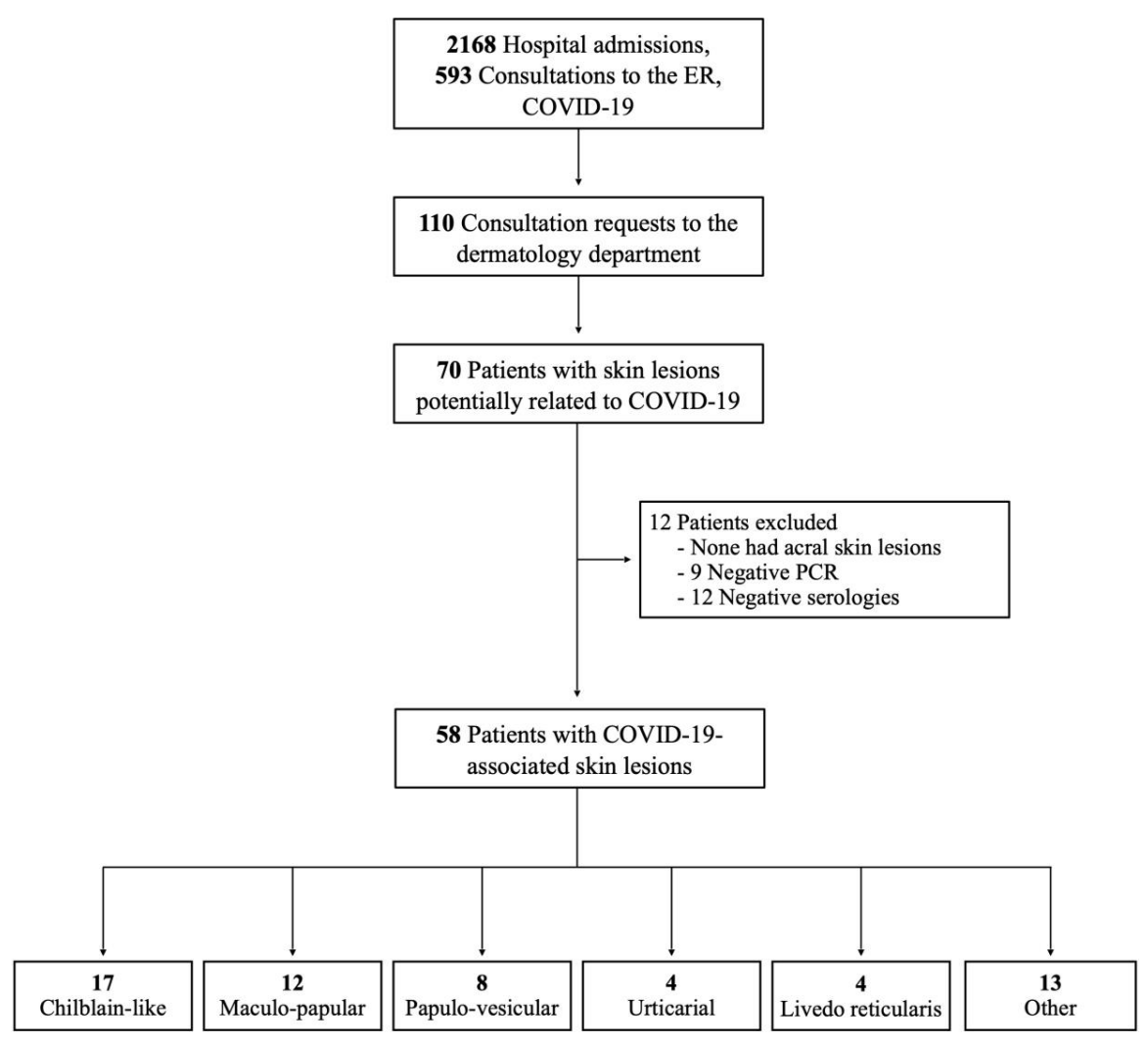

Figure 1. Patient flow chart according to STROBE standards.

Table 1 shows a summary of the patients' characteristics, both general and according to the clinicopathological patterns (see Table S1 (Supplementary Material) for an individually based account of patients' features, including histologic findings). Median age was 54.8 years (IQR, 38.7-69) and $46.6 \%$ were female. The chronological onset of cutaneous symptoms with respect to other type of symptoms and treatments are shown in Figure 2. 
Table 1. Basal characteristics of the 58 patients included in the study according to the dermatological skin patterns.

\begin{tabular}{|c|c|c|c|c|c|c|c|}
\hline Patient characteristics & $\begin{array}{l}\text { Chilblain-Like } \\
\quad(n=17)\end{array}$ & $\begin{array}{c}\text { Generalized } \\
\text { Maculo-Papular } \\
\text { Eruption }(n=12)\end{array}$ & $\begin{array}{l}\text { Grover's Disease and } \\
\text { Other Papulo-Vesicular } \\
\text { Eruptions }(n=8)\end{array}$ & $\begin{array}{c}\text { Urticarial } \\
\text { Eruption }(n=4)\end{array}$ & $\begin{array}{c}\text { Livedo } \\
\text { Reticularis } \\
(n=4)\end{array}$ & Other $*(n=13)$ & Total $(n=58)$ \\
\hline Female sex, $n(\%)$ & $7(41 \%)$ & $6(50 \%)$ & $4(50 \%)$ & $3(75 \%)$ & $1(25 \%)$ & $6(46 \%)$ & $27(47 \%)$ \\
\hline Median age, years (IQR) & $29(24.8,47.4)$ & $61(51,71.7)$ & $48(37.6,61.8)$ & $67(51.3,78.1)$ & $72(64.7,75.3)$ & $67(59.4,71.7)$ & $55(38.7,69.3)$ \\
\hline Immunosuppression, $n(\%)$ & $1(6 \%)$ & $1(8 \%)$ & 0 & 0 & 0 & $2(15 \%)$ & $4(7 \%)$ \\
\hline Hypertension, $n(\%)$ & 0 & $2(17 \%)$ & $3(37 \%)$ & $1(25 \%)$ & $2(50 \%)$ & $4(31 \%)$ & $12(21 \%)$ \\
\hline \multicolumn{8}{|l|}{ COVID-19 diagnosis, $n(\%)$} \\
\hline Confirmed & $7(41 \%)$ & $10(83 \%)$ & $6(75 \%)$ & $4(100 \%)$ & $4(100 \%)$ & $10(77 \%)$ & $41(71 \%)$ \\
\hline rt-PCR positive & $3(43 \%)$ & $9(90 \%)$ & $4(67 \%)$ & $3(75 \%)$ & $3(75 \%)$ & $7(64 \%)$ & $29(71 \%)$ \\
\hline Serology positive & $4(57 \%)$ & $2(20 \%)$ & $2(100 \%)$ & $1(25 \%)$ & $1(25 \%)$ & $3(100 \%)$ & $13(32 \%)$ \\
\hline Highly suspected & $10(59 \%)$ & $2(17 \%)$ & $2(25 \%)$ & 0 & 0 & $3(23 \%)$ & $17(29 \%)$ \\
\hline COVID-19 symptoms other than cutaneous, $n(\%)$ & $9(53 \%)$ & $12(100 \%)$ & $8(100 \%)$ & $4(100 \%)$ & $4(100 \%)$ & $13(100 \%)$ & $50(86 \%)$ \\
\hline Chest X-ray performed, $n(\%)$ & 5 & 11 & 8 & 4 & 4 & 13 & 44 \\
\hline Normal & $3(60 \%)$ & $1(9 \%)$ & $1(12 \%)$ & $1(25 \%)$ & 0 & $1(8 \%)$ & $7(16 \%)$ \\
\hline Unilateral interstitial infiltrates & 0 & 0 & 0 & 0 & 0 & $2(16.7 \%)$ & $2(4.5 \%)$ \\
\hline Bilateral interstitial infiltrates & $2(40 \%)$ & $10(91 \%)$ & $6(75 \%)$ & $3(75 \%)$ & $4(100 \%)$ & $8(67 \%)$ & $33(75 \%)$ \\
\hline Other & 0 & 0 & $1(12 \%)$ & 0 & 0 & $1(8 \%)$ & $2(4 \%)$ \\
\hline Blood test with altered values suggesting COVID-19, $n(\%)$ & $3(19 \%)$ & $11(100 \%)$ & $7(87 \%)$ & $2(100 \%)$ & $3(100 \%)$ & $13(100 \%)$ & $39(74 \%)$ \\
\hline Skin biopsy performed, $n(\%)$ & $12(71 \%)$ & $11(92 \%)$ & $6(75 \%)$ & $4(100 \%)$ & $4(100 \%)$ & $5(38 \%)$ & $42(72 \%)$ \\
\hline DIF performed, $n(\%)$ & $11(65 \%)$ & $3(25 \%)$ & $4(50 \%)$ & $3(75 \%)$ & $4(100 \%)$ & $5(38 \%)$ & $30(52 \%)$ \\
\hline "Antiviral" treatment, $n(\%)$ & $1(6 \%)$ & $10(83 \%)$ & $6(75 \%)$ & $4(100 \%)$ & $4(100 \%)$ & $11(85 \%)$ & $36(62 \%)$ \\
\hline Anti-inflammatory treatment, $n(\%)$ & $1(6 \%)$ & $10(83 \%)$ & $6(75 \%)$ & $4(100 \%)$ & $4(100 \%)$ & $11(85 \%)$ & $36(62 \%)$ \\
\hline Hospitalization required & $2(11.8 \%)$ & $10(83.3 \%)$ & $6(75 \%)$ & $4(100 \%)$ & $4(100 \%)$ & $12(92.3 \%)$ & $38(65.5 \%)$ \\
\hline ICU required & $1(6 \%)$ & $4(33 \%)$ & $3(37 \%)$ & $3(75 \%)$ & $2(50 \%)$ & $6(46 \%)$ & $19(33 \%)$ \\
\hline In-hospital mortality & 0 & 0 & $6(75 \%)$ & 0 & 0 & $2(5 \%)$ & $2(3 \%)$ \\
\hline
\end{tabular}

rt-PCR: Real-time polymerase chain reaction; DIF: Direct immunofluorescence; ICU: intensive care unit. * This group includes: pressure-induced ischemic necrosis in prolonged coma graft-versus-host disease $(n=1)$, stasis dermatitis $(n=1)$, dermatophytosis $(n=1)$, eruptive cherry angiomas $(n=1)$. 


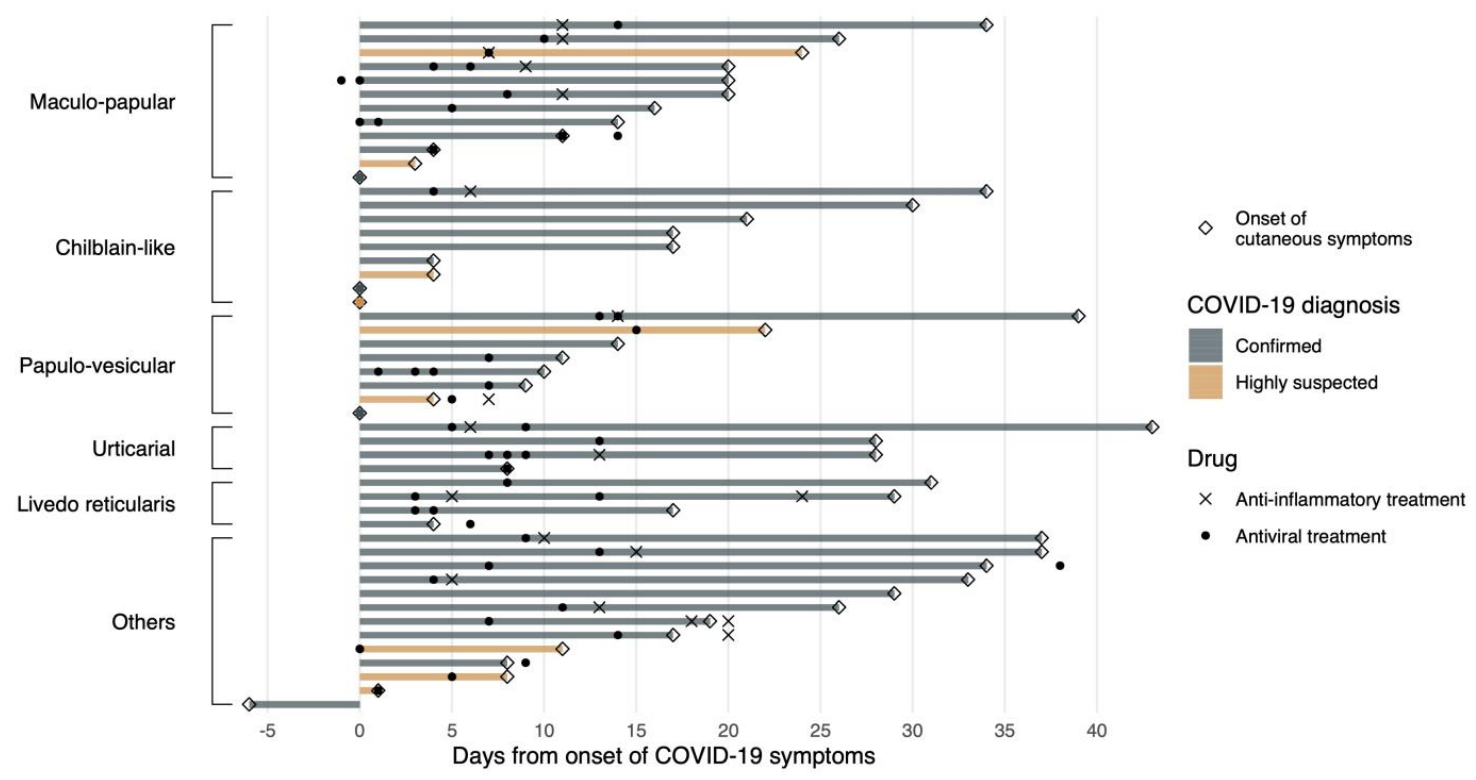

Figure 2. Swimmers plot showing the relationship between the onset of cutaneous manifestations with respect to other COVID-19 related symptoms. The figure also shows the initiation of treatment according to confirmed or highly suspected cases. When more than one treatment appears in a single patient, it indicates the initiation of a different type of drug (either antiviral or anti-inflammatory) along time.

Skin lesions were categorized into the following patterns: 17 chilblain-like $(29 \%), 12$ generalized maculo-papular eruptions (21\%), 8 papulo-vesicular eruptions (14\%), 4 livedo reticularis $(7 \%)$, 4 urticarial eruptions (7\%), and 13 other types of eruptions (22\%). See Figure 3 and Figures S1-S4 (Supplementary Material) in Selected Case Studies in Supplementary Material.
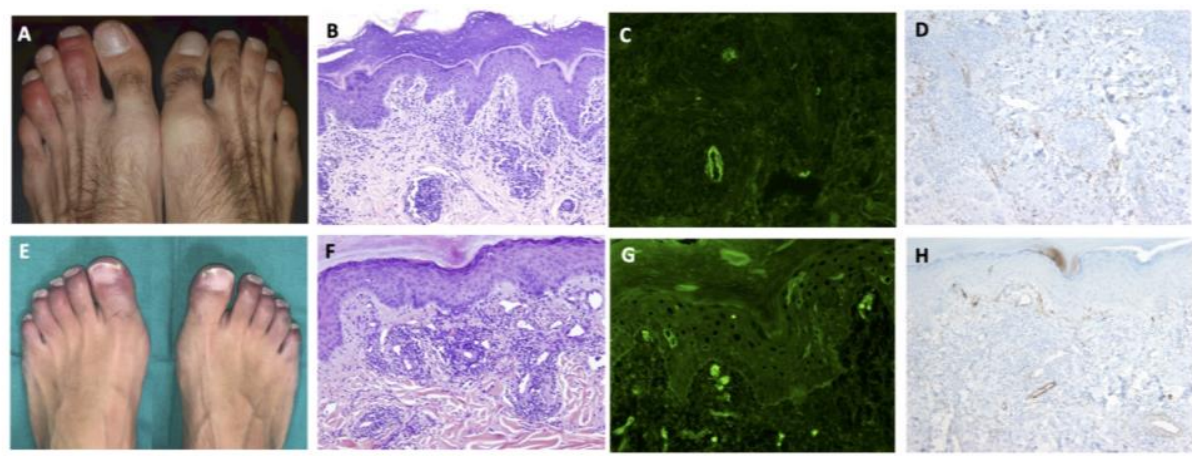

Figure 3. Clinical, histologic, and immunopathologic features of two cases with chilblain-like lesions. (A) Patient 2 Table S1. Painful chilblain-like lesions on toes; (B) Lichenoid dermatitis with perivascular and periadnexal lymphocytic infiltration on superficial and deep dermis. (Hematoxylin and eosin stain, original magnification $\times 100$ ); (C) Granular IgM deposition in dermal vessels (Direct immunofluorescence, original magnification $\times 200$ ); (D) C9 reactivity in dermal vessels (Immunohistochemistry, original magnification $\times 100$ ); (E) Patient 8 Table S1. Chilblain-like violaceus lesions on toes; (F) Perivascular and perianexial lymphocytic infiltration on superficial and mid dermis. (Hematoxylin and eosin stain, original magnification $\times 100$ ); (G) Granular C3 deposition in superficial dermal vessels (Direct immunofluorescence, original magnification $\times 200$ ); $(\mathbf{H})$ C9 reactivity in dermal vessels (Immunohistochemistry, original magnification $\times 100$ ).

Skin biopsies were performed in $42(72 \%)$ patients and included DIF in $30(52 \%)$, and IHC in $35(60 \%)$. 
Table 2 shows a comparison of the characteristics of patients with chilblain-like versus the other types of cutaneous lesions. Patients with chilblain-like lesions were significantly younger; had significantly lower percentages of microbiological confirmation, respiratory and systemic symptoms, and radiological and analytical abnormalities; were less frequently treated; and had lower hospital and ICU admission rates. In all cases except one, skin lesions appeared after the classic symptoms of COVID-19 (Figure 2). No specific association with autoantibodies was found. Histologic examination could be done in 12 of the $17(70.6 \%)$ patients with chilblain-like lesions. In addition, $11(64.7 \%)$ of them underwent DIF: in 7 of them (63.6\%), deposition of $\operatorname{IgM}$ or IgG, C3, and fibrinogen on dermal blood vessels suggested a vasculopathic pattern. This was confirmed by the presence of vascular C9 deposits by IHC observed in most of these patients (90.9\%, 10 of the 11 studied cases).

Table 2. Comparison of the characteristics of patients presenting with Chilblain-like. lesions and other types of skin lesions.

\begin{tabular}{|c|c|c|c|}
\hline Patient characteristics & Chilblain-Like $(n=17)$ & Others $(n=41)$ & $p$ Value \\
\hline Female sex, $n(\%)$ & $7(41 \%)$ & $20(49 \%)$ & 0.773 \\
\hline Median age, years (IQR) & $29(24,47)$ & $63(50,74)$ & $<0.001$ \\
\hline Immunosuppression, $n(\%)$ & $1(6 \%)$ & $3(7 \%)$ & 1.000 \\
\hline Hypertension, $n(\%)$ & 0 & $12(29 \%)$ & 0.012 \\
\hline ACE- $i$ and ARBs use & 0 & $6(15 \%)$ & 0.166 \\
\hline COVID-19 diagnosis, $n(\%)$ & & & 0.003 \\
\hline Confirmed & $7(41.2 \%)$ & $34(82.9 \%)$ & \\
\hline Highly suspected & $10(58.8 \%)$ & $7(17.1 \%)$ & \\
\hline \multicolumn{4}{|l|}{ COVID-19 symptoms other than cutaneous, $n(\%)$} \\
\hline Fever & $4(23 \%)$ & $35(85 \%)$ & $<0.001$ \\
\hline Cough & $6(35 \%)$ & $26(63 \%)$ & 0.050 \\
\hline Dyspnea & $1(6 \%)$ & $23(56 \%)$ & $<0.001$ \\
\hline Asthenia & $1(6 \%)$ & $15(37 \%)$ & 0.023 \\
\hline Myalgias & $1(6 \%)$ & $14(34 \%)$ & 0.045 \\
\hline Diarrhea & $1(6 \%)$ & $12(29 \%)$ & 0.082 \\
\hline Ageusia & $2(12 \%)$ & $8(19 \%)$ & 0.707 \\
\hline Anosmia & $2(12 \%)$ & $5(12 \%)$ & 1.000 \\
\hline Headache & 0 & $4(10 \%)$ & 0.310 \\
\hline Vomit & 0 & $3(7 \%)$ & 0.548 \\
\hline Chest X-ray performed, $n(\%)$ & $5(29 \%)$ & $39(95 \%)$ & $<0.0010 .060$ \\
\hline Normal & $3(60 \%)$ & $4(10 \%)$ & \\
\hline Unilateral interstitial infiltrates & 0 & $2(5 \%)$ & \\
\hline Bilateral interstitial infiltrates & $2(40 \%)$ & $31(79 \%)$ & \\
\hline Other & 0 & $2(5 \%)$ & \\
\hline \multicolumn{4}{|l|}{ COVID-19 related parameters } \\
\hline C-Reactive protein, median mg/dL (IQR) & $0.4(0.4,0.4)$ & $5.9(3.0,14.9)$ & 0.011 \\
\hline Lymphocytes, median cells ^106 (L (IQR) & $1800(1200,2000)$ & $800(600,1200)$ & $<0.001$ \\
\hline Ferritin, median ng/mL (IQR) & $87.5(40,197.2)$ & $615(232.5,905.2)$ & 0.013 \\
\hline LDH, median U/L (IQR) & $177(164.2,190.8)$ & $299(243.0,415.0)$ & 0.120 \\
\hline D-dimer, median ng/mL (IQR) & $200(200,300)$ & $800(500,2000)$ & 0.297 \\
\hline ESR, median mm/h (IQR) & $5(4,7)$ & $38.0(29,61.8)$ & $<0.001$ \\
\hline \multicolumn{4}{|l|}{ Autoimmunity test performed, $n(\%)$} \\
\hline Anti-nuclear antibodies & $15(88.2)$ & $22(53.6)$ & \\
\hline Positive & $3(20 \%)$ & $1(4 \%)$ & 0.283 \\
\hline Anti-Ro antibodies & $12(70 \%)$ & $20(49 \%)$ & \\
\hline Positive & 0 & 0 & $\mathrm{NC}$ \\
\hline Antibeta-2-glycoprotein antibodies, IgM & $15(88.23)$ & $24(58.53)$ & \\
\hline Positive & 0 & 0 & $\mathrm{NC}$ \\
\hline Antibeta-2-glycoprotein antibodies, IgG & $15(88.2)$ & $24(58.5)$ & \\
\hline Positive & $1(7 \%)$ & $2(8 \%)$ & 1.000 \\
\hline Anticardiolipin antibodies, $\mathrm{IgM}$ & $15(88.2)$ & $24(58.5)$ & \\
\hline Positive & 0 & 0 & NC \\
\hline Anticardiolipin antibodies, IgG & $15(88.2)$ & $24(58.5)$ & \\
\hline Positive & $2(13 \%)$ & $2(8 \%)$ & 0.631 \\
\hline Skin biopsy performed, $n(\%)$ & $12(77 \%)$ & $30(73 \%)$ & 1.000 \\
\hline Histological pattern according to HE stains & & & 0.003 \\
\hline Chilblain-like pattern & $10(83 \%)$ & 0 & \\
\hline
\end{tabular}


Table 2. em Cont.

\begin{tabular}{|c|c|c|c|}
\hline Patient characteristics & Chilblain-Like $(n=17)$ & Others $(n=41)$ & $p$ Value \\
\hline Spongiotic dermatitis & 0 & $8(27 \%)$ & \\
\hline Interface + spongiotic dermatitis & 0 & $6(20 \%)$ & \\
\hline Grover's disease pattern & 0 & $3(10 \%)$ & \\
\hline Urticariform & 0 & $2(7 \%)$ & \\
\hline Interface dermatitis & 0 & $2(7 \%)$ & \\
\hline Pityrosporum folliculitis & 0 & $2(7 \%)$ & \\
\hline Subcorneal pustulosis & 0 & $2(\%)$ & \\
\hline Psoriasiform & $1(8 \%)$ & 0 & \\
\hline Thrombotic microangiopathy & $1(8 \%)$ & $1(3 \%)$ & \\
\hline Other & 0 & $4(13 \%)$ & \\
\hline Mucin deposits & $9(75 \%)$ & $1(3 \%)$ & $<0.001$ \\
\hline Epidermal atrophy & $3(25 \%)$ & $2(7 \%)$ & 0.131 \\
\hline DIF performed, $n(\%)$ & $11(65 \%)$ & $19(46 \%)$ & 0.024 \\
\hline Lichenoid & 0 & $2(10.5 \%)$ & \\
\hline Lichenoid + vasculopathic & $3(27 \%)$ & 0 & \\
\hline Negative & $4(36 \%)$ & $14(74 \%)$ & \\
\hline Vasculopathic & $4(36 \%)$ & $3(15.8 \%)$ & $<0.001$ \\
\hline IHQ Anti-C9 deposits in dermal vessels performed, $n(\%)$ & $11(64.7)$ & $22(53.5)$ & \\
\hline Positive & $10(91 \%)$ & $5(23 \%)$ & $<0.001$ \\
\hline \multicolumn{4}{|l|}{ Treatment } \\
\hline Hydroxychloroquine & $1(6 \%)$ & $35(85 \%)$ & $<0.001$ \\
\hline Azithromycin & 0 & $34(83 \%)$ & $<0.001$ \\
\hline Lopinavir/ritonavir & $1(6 \%)$ & $29(71 \%)$ & $<0.001$ \\
\hline Systemic corticosteroids & $1(6 \%)$ & $24(58 \%)$ & $<0.001$ \\
\hline Tocilizumab & $1(6 \%)$ & $14(34 \%)$ & 0.045 \\
\hline Remdesivir & 0 & $5(12 \%)$ & 0.308 \\
\hline Anakinra & 0 & $5(12 \%)$ & 0.308 \\
\hline Siltuximab & 0 & $2(5 \%)$ & 1.000 \\
\hline Hospitalization required & $2(12 \%)$ & $36(88 \%)$ & $<0.001$ \\
\hline ICU required & $1(6 \%)$ & $18(44 \%)$ & 0.005 \\
\hline Mortality & 0 & $2(5 \%)$ & 1.000 \\
\hline
\end{tabular}

ACEi: angiotensin-converting enzyme inhibitors; ARBs: Angiotensin II receptor antagonists; ESR: erythrocyte sedimentation rate; H/E: hematoxylin-eosin; DIF: Direct immunofluorescence; IHQ: immunohistochemistry; ICU: intensive care unit; NC: Not calculable.

PCR tests on chilblains patients were performed in all cases when the "other symptoms associated with COVID-19" had already been resolved. In patients who presented without other symptoms associated with COVID-19, PCR was performed at least one week after the chilblains' appearance. In cases where serology was performed, it was done at the same time as PCR.

Twelve patients presented with generalized maculo-papular eruptions (Figure S1), and histology showed spongiotic dermatitis, interface dermatitis, or mixed patterns (interface plus spongiotic dermatitis). In 4 patients with urticarial eruptions, histology was compatible with urticaria (Figure S2). These 2 clinicopathological groups of patients were frequently taking many medications, and therefore, the differential diagnosis between skin lesions related to COVID-19 infection or a drug eruption can very difficult, if not impossible, to do with the exception of the few patients that were not taking any medication.

Eight patients presented with papulo-vesicular eruptions on the trunk. In three of them, histology showed intraepidermal vesicles with suprabasal acantholysis with the presence of dyskeratotic keratinocytes, typical of Grover's disease (Figure S3). In addition, there were 2 patients with chickenpox, 1 patient with herpes zoster, and 2 patients with Pityrosporum folliculitis. The time from the beginning of respiratory symptoms to the appearance of infectious lesions was variable. Four and 11 days for the two patients with folliculitis, 14 days for the patient with shingles, and 14 days for one of the patient's chickenpox. The other patient with chickenpox started with skin lesions at the same time as with respiratory symptoms.

Among the 58 patients included, 39 presented cough and dyspnea. Regarding these respiratory symptoms, which were the most frequently found about the COVID-19 infection, skin lesions' time of appearance was variable. Acral lesions $(n=6)$ appeared in a median time of 10.5 days (range: 4-26.8 days) after respiratory symptoms. In the rash maculopapular group $(n=8)$, these lesions appeared in 
a median of 18 days (range 13.2-24.5 days). Papulo-vesicular lesions $(n=7)$ were observed in a median of 11 days (range $7-18$ days). The group of urticarial lesions $(n=3)$ appeared in a median of 28 days (range 28-35.5 days). Lesions of livedo-reticularis $(n=4)$ appeared in a median of 23 days (range 13.8-29.5 days), and in the group of other lesions, they appeared in a median of 19 days (range $9.5-33.5$ days).

\section{Discussion}

Our findings suggest that skin lesions are a relatively uncommon manifestation of COVID-19 and emphasize the importance of histopathology in the characterization of skin lesions during the COVID-19 pandemic. The availability of skin biopsies, together with the specific traits of chilblain-like patterns in COVID-19, appears to be the cornerstone of COVID-19-associated skin lesions, allowing for their characterization and particularly their differentiation from other entities. Moreover, differentiating chilblain-like lesions from idiopathic and lupus-associated chilblain lesions, and other types of lesions such as generalized maculopapular or urticarial eruptions from drug reactions, is essential, given the frequency and characteristics of the former and the difficulties posed by the latter due to the large number of drugs usually concomitantly received by COVID-19 patients.

Inspired by Galván-Casas et al. proposed classification [17], we divided the cutaneous lesions into the following six groups: (1) Chilblain-like lesions, (2) Generalized maculopapular eruptions, (3) Grover's disease and other papulo-vesicular eruptions, (4) Livedo reticularis, (5) Urticarial eruptions, (6) Other eruptions: lesions that did not meet any of the previous criteria. These skin manifestations are represented by the acronym "GROUCH": Generalized maculo-papular; Grover's disease and other papulo-vesicular; livedo Reticularis; Other eruptions; Urticarial; and CHilblain-like.

This study provides a comprehensive picture of skin lesions of COVID-19 supported by histopathology studies, including DIF and IHC. Compared to other studies published to date, ours has four main strengths. First, our study provides histopathology data in the majority of cases. To date, just short series of cases have provided data on biopsy findings in all patients, whereas others only provided this information in a small proportion of patients $[15,17,18]$. Second, we provide an accurate description of the prevalence of skin lesions in COVID-19 patients. Third, all the cases included in our study had microbiologically-confirmed or highly-suspected COVID-19, whereas the vast majority of prior reports, with some exceptions such as that of Marzano and colleagues' study [18], included a notable proportion of patients that might not have been infected by SARS-CoV-2. Fourth, the detailed information on clinical manifestations other than cutaneous, radiological findings, analytical parameters, and particularly comprehensive histopathology data including immunofluorescence and IHC allowed us to better characterize the chilblain-like pattern as having largely specific features.

A large proportion of patients in our study did not fall in any of the 5 categories described by Galván-Casas and colleagues [17] and nonetheless presented interesting features that might be related to specific pathophysiological pathways triggered by SARS-CoV-2. For instance, four of these patients presented with acro-ischemia, and in two of them, these changes seemed to be related to vasoactive drug use; clear predisposing factors were not found in the other two cases. In a series of seven cases with acral necrosis, alterations in coagulation were observed, as well as four specific criteria of disseminated intravascular coagulation [19]. Zhang and colleagues described acro-ischemia in the context of antiphospholipid syndrome triggered by COVID-19 [20]. We found other types of vasculopathy in our series, as one case of retiform purpura with necrotic areas and three cases of livedo reticularis. Cases of transient livedo reticularis have been described in patients with COVID-19, but histologic studies were not performed [21]. Livedo reticularis can be idiopathic or associated with neoplasms, autoimmune or infectious diseases, among others, and it is also frequently observed in states of hypercoagulability [22]. One of the patients in our series presented concurrent pulmonary embolism and cutaneous intravascular thrombi, whereby DIF showed the deposition of IgM, C3, and fibrinogen within superficial-to-deep dermal blood vessel walls. In addition, C9 deposition was also demonstrated on the vessel walls by IHC [23]. 
Chilblain-like lesions related to COVID-19 infection have been mostly described in children and young adults $[12,15,24,25]$. In line with previous reports, patients with chilblain-like lesions in our series were younger, rarely presented systemic symptoms, and presented significantly fewer blood tests and radiological abnormalities compared with patients presenting other type of skin lesions. In addition, we found that these patients rarely required hospital admission and only exceptionally ICU admission. In our series, $41 \%$ of the patients with chilblain-like lesions had a confirmed diagnosis of COVID-19 whereas most cases reported elsewhere did not report this information. It is noteworthy that many of the chilblain's patients did not have positive rt-PCR or serology. rt-PCR can be negative because chilblain occurs several days after systemic symptoms (when rt-PCR could have been negative). In other cases, chilblains appear in isolation without other symptoms, and these patients may not already have the virus present in their pharynx. Serology is negative because perhaps these clinical manifestations are mediated by cellular immunity and do not produce circulating antibodies against COVID-19. All these are hypotheses that have not been demonstrated. We believe that more studies are needed to understand the physiopathology of cashew nuts related to COVID-19.

In one study, the dermatological characteristics of 132 acral lesions in patients with suspected COVID-19 were described; skin biopsies, however, were not performed, and only $18.1 \%$ of patients had a definite COVID-19 diagnosis [14]. It has been hypothesized that these lesions begin as erythematous-violaceous macules-papules that evolve to produce subsequent blisters or digital swelling; we did not, however, observe this evolutionary pattern. The performance of histologic studies in patients with chilblain-like lesions in our series showed characteristic features in COVID-19-related chilblain-like lesions. In the HE examination, patients with chilblain-like lesions showed intense perivascular (lymphocytic vasculitis) and peri-eccrine lymphocytic infiltrations that, in many cases, also affected the subcutaneous tissue, as previously described [24,25]. In addition, prominent lichenoid dermatitis and abundant dermal and hypodermal mucin deposition could be seen. DIF showed immunoglobulin M (or G), complement, and fibrinogen deposits in the dermal blood vessels; and vascular C9 deposits were observed by IHC in most patients. In addition, CD3/CD4 positive lymphocytes with small aggregates of $\mathrm{CD} 123$ positive cells within inflammatory infiltrates could be observed in some of the cases. Many of these histological findings can be found both in idiopathic chilblain or in chilblain lupus, but the presence of abundant mucin deposition is more suggestive of chilblain lupus [25]. However, the climatological conditions (spring) were very unusual for chilblain, and none of these patients either had other clinical manifestations compatible with lupus nor positive anti-Ro antibodies, therefore suggesting that these lesions were indeed induced by SARS-CoV-2. Remarkably, in the histologic study on necropsies of patients who died due to COVID-19, Varga and colleagues found viral particles inside endothelial cells along with an accumulation of inflammatory cells [26]. In our study, we found that most chilblain-like lesions had a vasculopathic pattern, with DIF and IHC findings suggestive of complement pathway activation. We can hypothesize that in the setting of COVID-19 these changes may be secondary to the arrival of viral particles to the distal circulation. $[27,28]$ Another interesting observation is that patients with monogenic type I interferonopathies (familial chilblain lupus, Aicardi-Goutières syndrome) that lead to type I interferon overproduction develop chilblain-like lesions [29]. Therefore, an exciting hypothesis to explain this type of lesions in patients with COVID-19 would be that specific immunologic repertoires present prior to SARS-CoV-2 could lead to different clinicopathological presentations. Patients who are able to develop an intense interferon response to the virus will develop mild systemic infection and chilblain-like lesions, while patients who are unable to produce interferon will develop a severe infection $[27,30]$.

Finally, changes suggesting viral infection have been found in previous reports of papulo-vesicular lesions in COVID-19 patients $[14,15,18]$. In our series, in three of these patients, histology was suggestive of Grover's disease, while the others had chickenpox, herpes zoster or Pityrosporum folliculitis. We believe that a proportion of COVID-19-associated skin lesions presenting a papulo-vesicular pattern correspond to the "pseudo-herpetic" variant of Grover's disease [31-33]. This is particularly relevant in the differential diagnosis with other viral-induced vesicular lesions. 
The main limitation of the study was a short inclusion period, therefore preventing us to provide a complete epidemiology description of COVID-19-associated lesions. Moreover, although this study provides detailed histology data in a larger proportion of patients with COVID-19 and cutaneous lesions, skin biopsy was not performed in all patients. Furthermore, a potential selection bias should be considered, since this is a single-center study carried out in a tertiary reference hospital providing care to adults but not patients in pediatric ages. Patients with skin lesions potentially related to COVID-19 with milder clinical presentations might have not been detected. Nevertheless, most patient with symptoms suggesting COVID-19 were seen at the hospital rather than the primary care during the peak of the pandemic in Barcelona, and almost all private dermatology practice was discontinued during this period as well. In addition, chilblain-like lesions associated with COVID-19 are more frequent in children and young adults; hence, the prevalence of chilblain-like lesions in our series might be lower than in the community. Finally, isolation and contact prevention measures in the hospital's routine practices during the pandemic caused difficulties with complete skin exams. Consequently, some asymptomatic or pauci-symptomatic skin lesions might have passed unnoticed.

In conclusion, our data showed that skin lesions affect around 2\% of patients with COVID-19 and can present with various patterns that can be summarized by the acronym GROUCH. Notably, patients with chilblain-like lesions have distinctive clinical and histological features and have less severe manifestations of the disease. The different clinico-pathologic patterns observed in the present study may be due to specific immunologic repertoires. Further studies are required to better define the histopathology traits, including the presence of viral particles and genetic material, as well as the immunological blueprint of COVID-19-associated skin lesions.

Supplementary Materials: The following are available online at http://www.mdpi.com/2077-0383/9/10/3261/s1, Figure S1: Patient 21 from Table S1, Figure S2: Patient 35 from Table S1, Figure S3: Patient 32 from Table S1, Figure S4: Patient 35 from Table S1; Table S1: Case-by-case description of the 58 patients included in the study.

Author Contributions: P.G., S.P. (Sebastián Podlipnik), J.M.P., S.P. (Susana Puig), and J.M.M.J. conceived and designed the study; S.P. (Sebastián Podlipnik) performed the statistical analyses; P.G. and J.M.P. drafted the manuscript; all other authors collected data, critically revised the manuscript, and provided final approval. All authors have read and agreed to the published version of the manuscript.

Funding: This research received no external funding.

Acknowledgments: To the entire Dermatology team of the Hospital Clínic de Barcelona, who worked intensively during the COVID-19 pandemic: Mercè Alsina, Josep Malvehy, Encarnación Martín, Paula Aguilera, Lorena Barboza-Gudagnini, Sara Gómez-Armayones, Javiera Pérez-Anker, Natalia Espinosa, and Teresa Estrach. The patients in this manuscript have given written informed consent to publication of their case details.

Conflicts of Interest: The authors declare no conflict of interest.

\section{References}

1. COVID-19 Map. Available online: https://coronavirus.jhu.edu/map.html (accessed on 3 May 2020).

2. Wu, Z.; McGoogan, J.M. Characteristics of and Important Lessons From the Coronavirus Disease 2019 (COVID-19) Outbreak in China: Summary of a Report of 72,314 Cases From the Chinese Center for Disease Control and Prevention. JAMA 2020, 323, 1239-1242. [CrossRef]

3. Pericàs, J.M.; Hernández-Meneses, M.; Sheahan, T.P.; Quintana, E.; Ambrosioni, J.; Sandoval, E.; Falces, C.; Marcos, M.A.; Tuset, M.; Vilella, A.; et al. COVID-19: From Epidemiology to Treatment. Eur Heart J. 2020, 41, 2092-2112. [CrossRef]

4. Marini, J.J.; Gattinoni, L. Management of COVID-19 Respiratory Distress. JAMA 2020, 323, $2329-2330$. [CrossRef]

5. Bikdeli, B.; Madhavan, M.V.; Jimenez, D.; Chuich, T.; Dreyfus, I.; Driggin, E.; Nigoghossian, C.D.; Ageno, W.; Madjid, M.; Guo, Y.; et al. COVID-19 and Thrombotic or Thromboembolic Disease: Implications for Prevention, Antithrombotic Therapy, and Follow-up. J. Am. Coll. Cardiol. 2020, 75, 2950-2973. [CrossRef]

6. Mo, X.; Jian, W.; Su, Z.; Chen, M.; Peng, H.; Peng, P.; Lei, C.; Li, S.; Chen, R.; Zhong, N. Abnormal pulmonary function in COVID-19 patients at time of hospital discharge. Eur. Respir. J. 2020, 55, 2001217. [CrossRef] 
7. Sanders, J.M.; Monogue, M.L.; Jodlowski, T.Z.; Cutrell, J.B. Pharmacologic Treatments for Coronavirus Disease 2019 (COVID-19): A Review. JAMA 2020, 323, 1824-1836. [CrossRef]

8. Guan, W.; Ni, Z.; Hu, Y.; Liang, W.; Ou, C.; He, J.; Liu, L.; Shan, H.; Lei, C.; Hui, D.S.C.; et al. Clinical Characteristics of Coronavirus Disease 2019 in China. N. Engl. J. Med. 2020, 382, 1708-1720. [CrossRef]

9. Richardson, S.; Hirsch, J.S.; Narasimhan, M.; Crawford, J.M.; McGinn, T.; Davidson, K.W.; The Northwell COVID-19 Research Consortium; Barnaby, D.P.; Becker, L.B.; Chelico, J.D.; et al. Presenting Characteristics, Comorbidities, and Outcomes Among 5700 Patients Hospitalized With COVID-19 in the New York City Area. JAMA 2020, 323, 2052-2059. [CrossRef]

10. Recalcati, S. Cutaneous manifestations in COVID-19: A first perspective. J. Eur. Acad. Dermatol. Venereol. 2020. [CrossRef]

11. Diaz-Guimaraens, B.; Dominguez-Santas, M.; Suarez-Valle, A.; Pindado-Ortega, C.; Selda-Enriquez, G.; Bea-Ardebol, S.; Fernandez-Nieto, D. Petechial Skin Rash Associated With Severe Acute Respiratory Syndrome Coronavirus 2 Infection. JAMA Dermatol. 2020, 156, 820-822. [CrossRef]

12. Sanchez, A.; Sohier, P.; Benghanem, S.; L'Honneur, A.-S.; Rozenberg, F.; Dupin, N.; Garel, B. Digitate Papulosquamous Eruption Associated With Severe Acute Respiratory Syndrome Coronavirus 2 Infection. JAMA Dermatol. 2020, 156, 819-820. [CrossRef]

13. Piccolo, V.; Neri, I.; Filippeschi, C.; Oranges, T.; Argenziano, G.; Battarra, V.C.; Berti, S.; Manunza, F.; Belloni Fortina, A.; Di Lernia, V.; et al. Chilblain-like lesions during COVID-19 epidemic: A preliminary study on 63 patients. J. Eur. Acad. Dermatol. Venereol. 2020, 34, e291-e293. [CrossRef]

14. Fernandez-Nieto, D.; Jimenez-Cauhe, J.; Suarez-Valle, A.; Moreno-Arrones, O.M.; Saceda-Corralo, D.; Arana-Raja, A.; Ortega-Quijano, D. Characterization of acute acro-ischemic lesions in non-hospitalized patients: A case series of 132 patients during the COVID-19 outbreak. J. Am. Acad. Dermatol. 2020, 83, e61-e63. [CrossRef]

15. Recalcati, S.; Barbagallo, T.; Frasin, L.A.; Prestinari, F.; Cogliardi, A.; Provero, M.C.; Dainese, E.; Vanzati, A.; Fantini, F. Acral cutaneous lesions in the Time of COVID-19. J. Eur. Acad. Dermatol. Venereol. 2020, 34, e346-e347. [CrossRef]

16. Vandenbroucke, J.P.; von Elm, E.; Altman, D.G.; Gøtzsche, P.C.; Mulrow, C.D.; Pocock, S.J.; Poole, C.; Schlesselman, J.J.; Egger, M.; STROBE Initiative. Strengthening the Reporting of Observational Studies in Epidemiology (STROBE): Explanation and elaboration. PLoS Med. 2007, 4, e297. [CrossRef]

17. Galván Casas, C.; Català, A.; Carretero Hernández, G.; Rodríguez-Jiménez, P.; Fernández Nieto, D.; Rodríguez-Villa Lario, A.; Navarro Fernández, I.; Ruiz-Villaverde, R.; Falkenhain, D.; Llamas Velasco, M.; et al. Classification of the cutaneous manifestations of COVID-19: A rapid prospective nationwide consensus study in Spain with 375 cases. Br. J. Dermatol. 2020, 183, 71-77. [CrossRef]

18. Marzano, A.V.; Genovese, G.; Fabbrocini, G.; Pigatto, P.; Monfrecola, G.; Piraccini, B.M.; Veraldi, S.; Rubegni, P.; Cusini, M.; Caputo, V.; et al. Varicella-like exanthem as a specific COVID-19-associated skin manifestation: Multicenter case series of 22 patients. J. Am. Acad. Dermatol. 2020, 83, 280-285. [CrossRef]

19. Zhang, Y.; Cao, W.; Xiao, M.; Li, Y.J.; Yang, Y.; Zhao, J.; Zhou, X.; Jiang, W.; Zhao, Y.Q.; Zhang, S.Y.; et al. [Clinical and coagulation characteristics of 7 patients with critical COVID-2019 pneumonia and acro-ischemia]. Zhonghua Xueyexue Zazhi 2020, 41, E006.

20. Zhang, Y.; Xiao, M.; Zhang, S.; Xia, P.; Cao, W.; Jiang, W.; Chen, H.; Ding, X.; Zhao, H.; Zhang, H.; et al. Coagulopathy and Antiphospholipid Antibodies in Patients with Covid-19. N. Engl. J. Med. 2020, 382, e38. [CrossRef]

21. Manalo, I.F.; Smith, M.K.; Cheeley, J.; Jacobs, R. A Dermatologic Manifestation of COVID-19: Transient Livedo Reticularis. J. Am. Acad. Dermatol. 2020, 83, 700. [CrossRef]

22. Gibbs, M.B.; English, J.C.; Zirwas, M.J. Livedo reticularis: An update. J. Am. Acad. Dermatol. 2005, 52, 1009-1019. [CrossRef]

23. Bosch-Amate, X.; Giavedoni, P.; Podlipnik, S.; Andreu-Febrer, C.; Sanz-Beltran, J.; Garcia-Herrera, A.; Alós, L.; Mascaró, J.M., Jr. Retiform purpura as a dermatological sign of COVID-19 coagulopathy. J. Eur. Acad. Dermatol. Venereol. 2020. [CrossRef]

24. Cordoro, K.M.; Reynolds, S.D.; Wattier, R.; McCalmont, T.H. Clustered Cases of Acral Perniosis: Clinical Features, Histopathology and Relationship to COVID-19. Pediatr. Dermatol. 2020, 37, 419-423. [CrossRef] 
25. Wang, M.L.; Chan, M.P. Comparative Analysis of Chilblain Lupus Erythematosus and Idiopathic Perniosis: Histopathologic Features and Immunohistochemistry for CD123 and CD30. Am. J. Dermatopathol. 2018, 40, 265-271. [CrossRef]

26. Varga, Z.; Flammer, A.J.; Steiger, P.; Haberecker, M.; Andermatt, R.; Zinkernagel, A.S.; Mehra, M.R.; Schuepbach, R.A.; Ruschitzka, F.; Moch, H. Endothelial cell infection and endotheliitis in COVID-19. Lancet Lond. Engl. 2020, 395, 1417-1418. [CrossRef]

27. Magro, C.; Mulvey, J.J.; Laurence, J.; Sanders, S.; Crowson, N.; Grossman, M.; Harp, J.; Nuovo, G. The differing pathophysiologies that underlie COVID-19 associated perniosis and thrombotic retiform purpura: A case series. Br. J. Dermatol. 2020. [CrossRef]

28. Colmenero, I.; Santonja, C.; Alonso-Riaño, M.; Noguera-Morel, L.; Hernández-Martín, A.; Andina, D.; Wiesner, T.; Rodríguez-Peralto, J.L.; Requena, L.; Torrelo, A. SARS-CoV-2 endothelial infection causes COVID-19 chilblains: Histopathological, immunohistochemical and ultrastructural study of seven paediatric cases. Br. J. Dermatol. 2020. [CrossRef]

29. Figueras-Nart, I.; Mascaró, J.M.; Solanich, X.; Hernández-Rodríguez, J. Dermatologic and Dermatopathologic Features of Monogenic Autoinflammatory Diseases. Front. Immunol. 2019, 10, 2448. [CrossRef]

30. Trouillet-Assant, S.; Viel, S.; Gaymard, A.; Pons, S.; Richard, J.-C.; Perret, M.; Villard, M.; Brengel-Pesce, K.; Lina, B.; Mezidi, M.; et al. Type I IFN immunoprofiling in COVID-19 patients. J. Allergy Clin. Immunol. 2020, 146, 206-208. [CrossRef]

31. Capusan, T.M.; Herrero-Moyano, M.; Fraga, J.; Llamas-Velasco, M. Clinico-Pathological Study of 4 Cases of Pseudoherpetic Grover Disease: The Same as Vesicular Grover Disease. Am. J. Dermatopathol. 2018, 40, 445-448. [CrossRef]

32. Llamas-Velasco, M.; Chicharro, P.; Rodríguez-Jiménez, P.; Martos-Cabrera, L.; De Argila, D.; Fernández-Figueras, M.; Fraga, J. Reply to “Clinical and histological characterization of vesicular COVID-19 rashes: A prospective study in a tertiary care hospital": Pseudoherpetic Grover disease seems to appear in patients with COVID-19 infection. Clin. Exp. Dermatol. 2020. [CrossRef] [PubMed]

33. Fernández-Figueras, M.-T.; Puig, L.; Cannata, P.; Cuatrecases, M.; Quer, A.; Ferrándiz, C.; Ariza, A. Grover disease: A reappraisal of histopathological diagnostic criteria in 120 cases. Am. J. Dermatopathol. 2010, 32, 541-549. [CrossRef]

(C) 2020 by the authors. Licensee MDPI, Basel, Switzerland. This article is an open access article distributed under the terms and conditions of the Creative Commons Attribution (CC BY) license (http://creativecommons.org/licenses/by/4.0/). 